\section{Original Article}

Check for updates

\title{
Inhaled Corticosteroids in Asthma and the Risk of Pneumonia
}

\section{OPEN ACCESS}

Received: Jan 8, 2019

Revised: Jun 3, 2019

Accepted: Jun 3, 2019

Correspondence to

Jin Hwa Lee, MD, PhD

Department of Internal Medicine, College of Medicine, Ewha Womans University, 1071

Anyangcheon-ro, Yangcheon-gu, Seoul 07985, Korea.

Tel: +82-2-2650-6007

Fax: +82-2-2650-2076

E-mail: jinhwalee@ewha.ac.kr

Copyright (c) 2019 The Korean Academy of Asthma, Allergy and Clinical Immunology .

The Korean Academy of Pediatric Allergy and Respiratory Disease

This is an Open Access article distributed under the terms of the Creative Commons Attribution Non-Commercial License (https:// creativecommons.org/licenses/by-nc/4.0/) which permits unrestricted non-commercial use, distribution, and reproduction in any medium, provided the original work is properly cited.

ORCID iDs

Min-Hye Kim (D)

https://orcid.org/0000-0002-1775-3733

Chin Kook Rhee (D)

https://orcid.org/0000-0003-4533-7937

Ji-Su Shim (ID)

https://orcid.org/0000-0002-8846-0364 So Young Park (iD)

https://orcid.org/0000-0003-2718-0518

Kwang Ha Yoo (D)

https://orcid.org/0000-0001-9969-2657 Yun Su Sim (iD)

https://orcid.org/0000-0002-3746-4947

Jung Hyun Chang (D)

https://orcid.org/0000-0003-1000-2491

\author{
Min-Hye Kim (D), Chin Kook Rhee $\mathbb{B},{ }^{2}$ Ji-Su Shim $\mathbb{D},{ }^{1}$ So Young Park $\left(\mathbb{D},{ }^{1}\right.$ \\ Kwang Ha Yoo (1), ${ }^{3}$ Bo Yeon Kim, ${ }^{4}$ Hye Won Bae, ${ }^{4}$ Yun Su Sim $(D, 5$ \\ Jung Hyun Chang $\left(\mathbb{D},{ }^{1}\right.$ Young-Joo Cho $\left(\mathbb{D},,^{1}\right.$ Jin Hwa Lee $(\mathbb{1})^{*}$
}

'Department of Internal Medicine, College of Medicine, Ewha Womans University, Seoul, Korea ${ }^{2}$ Division of Pulmonary, Allergy and Critical Care Medicine, Department of Internal Medicine, Seoul St. Mary's Hospital, College of Medicine, The Catholic University of Korea, Seoul, Korea

${ }^{3}$ Division of Pulmonary, Allergy and Critical Care Medicine, Department of Internal Medicine, Konkuk University School of Medicine, Seoul, Korea

${ }^{4}$ Health Insurance Review and Assessment Service, Wonju, Korea

${ }^{5}$ Division of Pulmonary, Allergy and Critical Care Medicine, Department of Internal Medicine, Hallym University Kangnam Sacred Heart Hospital, Seoul, Korea

\section{ABSTRACT}

Purpose: Asthma is a common disease that is expensive and burdensome for patients. Inhaled corticosteroids (ICS) are the most important drugs for asthma treatment and are often prescribed long-term. However, the use of ICS has been reported to increase pneumonia, though this remains controversial. We evaluated whether the use of ICS increases the risk of pneumonia in asthmatic patients using the Health Insurance Review and Assessment Service (HIRA) database in Korea.

Methods: The Asthma Management Adequacy Assessment was performed by the HIRA in Korea. Patients with claimed insurance benefits for asthma disease codes and who were prescribed asthma medications more than 2 times were enrolled. Patient demographics, asthma medications, healthcare use, and complications were analyzed.

Results: The total number of asthma patients was 831,613. Patients using ICS were older and had more comorbidities than those not using ICS; they also visited outpatient clinics and emergency departments, and were more often hospitalized. Pneumonia and other complications occurred more often in patients using ICS, and they used more respiratory medications, except for theophylline. Multiple logistic regression analysis showed that ICS prescription was associated with pneumonia (odds ratio, 1.38; 95\% confidence interval, 1.361.41). Age, sex, medical care, use of secondary and tertiary hospitals, and hospitalization due to asthma in the previous year were also associated with pneumonia.

Conclusions: ICS use was associated with increasing pneumonia in asthmatic patients in Korea. Therefore, it is critical to acknowledge that the use of ICS may increase the risk of pneumonia and should be meticulously monitored in asthmatics.

Keywords: Pneumonia; asthma; steroids

\section{INTRODUCTION}

Asthma has a prevalence of $4.1 \% .{ }^{1}$ The cost of asthma exceeds $\$ 8,800$ per capita per year, and a recent investigation in Korea found that it costs affected patients more than $\$ 16,300$ per 
Young-Joo Cho iD

https://orcid.org/0000-0002-9414-5934

Jin Hwa Lee (iD)

https://orcid.org/0000-0003-0843-9862

Disclosure

CK Rhee received consulting/lecture fees from MSD, AstraZeneca, Novartis, GSK, Takeda, Mundipharma, Sandoz, Boehringer-Ingelheim, and Teva-Handok. Min-Hye Kim, Kwang Ha Yoo, Bo Yeon Kim, Hye Won Bae, Yun Su Sim, Jung Hyun Chang, Young-Joo Cho, and Jin Hwa Lee have no conflict of interest to declare. year in work losses. ${ }^{2}$ The direct cost of asthma in severely affected patients is approximately 10-foldgreater than in those with mild asthma. ${ }^{3,4}$ Asthma requires significant medical resources, and as costs increase along with asthma severity, management of asthma is imperative.

Inhaled corticosteroids (ICSs) are critical in the treatment of asthma. ICSs are the first drugs of choice in the controller medication category recommended by the Global Initiative for Asthma (GINA) guidelines. ${ }^{5}$ ICSs improve lung function and quality of life, reducing asthma symptoms, disease progression, and related mortality. ${ }^{6-8}$ However, some drawbacks to ICS use have been reported; in particular, ICS use can increase the risk of pneumonia in patients with chronic obstructive pulmonary disease (COPD). ${ }^{9-12}$ Associations between ICS use and the risk of pneumonia have not been observed with all types of ICS. They have mainly been reported for fluticasone ICS, but not for budesonide. ${ }^{13}$ Studies also have not demonstrated that the increased risk of pneumonia is accompanied by increased mortality. ${ }^{14}$ Additionally, most studies of the relationship between ICS and increased pneumonia risk have been conducted on COPD patients, with fewer studies involving asthma patients, and the results of the studies remain controversial. ${ }^{15,16}$ Some studies have reported that ICS use increases the risk of pneumonia in asthmatics, ${ }^{16,17}$ while other studies have reported no association between ICS use and pneumonia. ${ }^{15,18,19}$ Another suggested that ICS could act in a protective capacity against pneumonia. ${ }^{15}$ There is also very little data regarding ICS use and asthma in Korean patients. We evaluated whether the use of ICS increases the risk of pneumonia in asthmatic patients using data from the Asthma Management Adequacy Assessment performed by the Health Insurance Review and Assessment Service (HIRA) in Korea.

\section{MATERIALS AND METHODS}

\section{Study design}

Data from the Asthma Management Adequacy Assessment performed by the HIRA in Korea were analyzed. Asthma was the target disease, with disease codes J45.x and J46.x based on the Korean Standard Classification of Diseases version 6.0. Medical institutions were enrolled when primary to tertiary care institutions filed insurance claims for asthma (J45.x, J46.x) as a major disease code, or within the fifth minor disease codes, between July 2013 and June 2014. Claims data for medical care benefits for asthma (J45.x, J46.x) were analyzed, and study participants were the asthmatic patients on behalf of whom the claims were filed.

For the purpose of study participant selection, asthma was defined as follows: During the evaluation period, participants were aged 15 years or older with at least 2 outpatient visits, were treated with asthma medications or received inpatient care, and were using more than 1 systemic corticosteroid and at least 1 asthma medication at the time of the outpatient clinic visits. Asthma medications comprised ICS, long-acting $\beta 2$-agonists (LABA), long-acting muscarinic antagonists (LAMA), short-acting muscarinic antagonists (SAMA), short-acting $\beta 2$-agonists (SABA), leukotriene receptor antagonists (LTRA), and xanthine derivatives. This dataset also included age, sex, insurance type, hospital type, comorbidity and Charlson comorbidity index,${ }^{20}$ outpatient or emergency department (ED) visit, hospitalization to the general or intensive care unit (ICU), and complications. ICS users and non-ICS users were defined as patients who were or were not prescribed ICS during the study period, respectively. Pneumonia occurrence was defined via the presence or absence of disease codes for pneumonia, which range from J12.x to J18.x. Types of health insurance were divided into 2 categories: medical insurance, a program that is eligible to all people in South 
Korea and is used by over $96.3 \%$ of the total population; or medical aid, a program in which the government pays on behalf of patients who are unable to pay their medical expenses. This study protocol was approved by the Institutional Review Board (IRB) of the Catholic University of Korea, Seoul St. Mary's Hospital (IRB No. KC16RESI0560).

\section{Statistical analysis}

All data were expressed as mean \pm standard deviation, median value, or number (\%). Continuous variables were analyzed by Student's $t$ test or the Mann-Whitney $U$ test, and categorical variables were analyzed by the $\chi^{2}$ test or Fisher's exact test. Multiple logistic regression analysis was used to determine if ICSs are an independent factor associated with pneumonia occurrence. Unadjusted or adjusted odds ratio (OR) and $95 \%$ confidence intervals (CIs) were presented. A $P$ value of less than 0.05 was considered statistically significant. SAS ver. 9.2 (SAS Institute, Cary, NC, USA) was used for all statistical calculations and analyses.

\section{RESULTS}

Because we used data form Asthma Management Adequacy Assessment performed by the HIRA in Korea, the number of target organizations evaluated was limited to 16,804 sites, which accounted for $50.4 \%$ of a total of 33,341 sites. Forty-three sites were tertiary general hospitals $(0.3 \%), 280$ were secondary general hospitals $(1.7 \%)$, and 14,745 were primary clinics $(87.8 \%)$. The total number of asthma patients was 831,613 , and among them, the number of patients using tertiary general hospitals was 43,471(5.2\%), with 83,194 (10.0\%) using secondary general hospitals, and 686,063 (82.5\%) using primary care.

ICS users were older and more likely to be male than non-ICS users $(P<0.001)$. The proportions of ICS users who were medical aid patients and patients receiving care at secondary or tertiary hospitals were higher than those of non-ICS users $(P<0.001)$. All comorbidities, such as cardiovascular disease, diabetes mellitus, depressive disorder, allergic rhinitis, and malignancy, were more common in ICS users than in non-ICS users $(P<0.001)$, except for arthritis (Table 1). ICS users utilized more healthcare services: They visited outpatient clinics or EDs more often and were more frequently hospitalized to general wards or ICUs than non-ICS users $(P<0.001)$. The mean length of hospital stay was longer for ICS users than for non-ICS users, and the incidence of complications was higher in ICS users. Pneumonia, empyema, adult respiratory distress syndrome or acute respiratory failure, pneumothorax, and pneumomediastinum also occurred more often in ICS users than in non-ICS users (Table 2). ICS users received more prescriptions for respiratory drugs, including LABA, LAMA, LABA+LAMA, SAMA, SABA, SABA+SAMA, and LTRA as well as ICS and ICS+LABA, than non-ICS users. Conversely, the theophylline prescription rate was higher for non-ICS users than ICS users. LTRA and theophylline were most frequently prescribed in both groups (Table 3).

We selected among the previously analyzed factors to identify those associated with pneumonia. Asthma patients were divided into groups with pneumonia (pneumonia $[+]$ ) and without pneumonia (pneumonia [-]). The pneumonia (+) group was older and more likely to receive medical aid, utilized more secondary and tertiary hospitals, had a higher Charlson comorbidity index, had a higher hospitalization rate during the previous year, and had more ICS users than the pneumonia (-) group. In the univariate analyses, age, medical care, 
Table 1. Clinical characteristics according to inhaled corticosteroid use

\begin{tabular}{|c|c|c|c|c|c|}
\hline \multirow[t]{2}{*}{ Characteristics } & \multicolumn{2}{|c|}{$\operatorname{ICS}(-)$} & \multicolumn{2}{|c|}{$\operatorname{ICS}(+)$} & \multirow[t]{2}{*}{$P$ value } \\
\hline & No. & $\%$ & No. & $\%$ & \\
\hline Total & 447,855 & 100.0 & 281,488 & 100.0 & \\
\hline Age (yr) & $56.7 \pm 18.34$ & & $57.9 \pm 17.66$ & & $<0.001$ \\
\hline Male $(\%)$ & 172,121 & 38.4 & 121,641 & 43.2 & $<0.001$ \\
\hline Insurance type & & & & & $<0.001$ \\
\hline Medical insurance & 418,306 & 93.4 & 257,173 & 91.4 & \\
\hline Medical aid & 29,549 & 6.6 & 24,315 & 8.6 & \\
\hline \multicolumn{6}{|l|}{ Hospital type } \\
\hline Primary & 404,262 & 90.3 & 195,198 & 69.3 & $<0.001$ \\
\hline Secondary & 24,902 & 5.6 & 31,582 & 11.2 & $<0.001$ \\
\hline Tertiary & 37,647 & 8.4 & 120,396 & 42.8 & $<0.001$ \\
\hline \multicolumn{6}{|l|}{ Comorbidity } \\
\hline Ischemic heart disease & 9,515 & 2.1 & 11,676 & 4.1 & $<0.001$ \\
\hline Osteoporosis & 7,733 & 1.7 & 8,405 & 3.0 & $<0.001$ \\
\hline Depressive disorder & 3,617 & 0.8 & 4,086 & 1.5 & $<0.001$ \\
\hline Arthritis & 15,238 & 3.4 & 9,154 & 3.3 & $<0.001$ \\
\hline Diabetes mellitus & 28,774 & 6.4 & 27,581 & 9.8 & $<0.001$ \\
\hline Congestive heart failure & 4,879 & 1.1 & 6,035 & 2.1 & $<0.001$ \\
\hline Hypertension & 56,962 & 12.7 & 54,287 & 19.3 & $<0.001$ \\
\hline Anemia & 3,792 & 0.8 & 3,620 & 1.3 & $<0.001$ \\
\hline Metabolic syndrome & 21,577 & 4.8 & 26,028 & 9.2 & $<0.001$ \\
\hline Allergic rhinitis & 285,877 & 63.8 & 196,663 & 69.9 & $<0.001$ \\
\hline Malignancy & 2,585 & 0.6 & 5,521 & 2.0 & $<0.001$ \\
\hline Charlson comorbidity index & $1.3 \pm 0.65$ & & $1.4 \pm 18.28$ & & $<0.001$ \\
\hline
\end{tabular}

ICS, inhaled corticosteroids

Table 2. Asthma-related clinical characteristics according to inhaled corticosteroid use

\begin{tabular}{|c|c|c|c|c|c|}
\hline \multirow[t]{2}{*}{ Characteristics } & \multicolumn{2}{|c|}{$\operatorname{ICS}(-)$} & \multicolumn{2}{|c|}{$\operatorname{ICS}(+)$} & \multirow[t]{2}{*}{$P$ value } \\
\hline & No. & $\%$ & No. & $\%$ & \\
\hline Total & 447,855 & 100.0 & 281,488 & 100.0 & \\
\hline Outpatient visit $\geq 3$ times & 272,904 & 60.9 & 223,656 & 79.5 & $<0.001$ \\
\hline No. of outpatient visits & $4.6 \pm 5.33$ & & $6.4 \pm 6.88$ & & $<0.001$ \\
\hline ER visit & 2,197 & 0.5 & 14,560 & 5.2 & $<0.001$ \\
\hline No. of ER visits & $1.2 \pm 1.23$ & & $1.4 \pm 2.22$ & & $<0.001$ \\
\hline Hospitalization & 5,090 & 1.1 & 25,111 & 8.9 & $<0.001$ \\
\hline No. of hospitalizations & $1.3 \pm 0.77$ & & $1.5 \pm 1.08$ & & $<0.001$ \\
\hline ICU admission & 322 & 0.1 & 2,232 & 0.8 & $<0.001$ \\
\hline No. of ICU admissions & $1.1 \pm 0.32$ & & $1.2 \pm 0.53$ & & $<0.001$ \\
\hline Mean hospitalized days & $13.2 \pm 14.16$ & & $15.5 \pm 18.28$ & & $<0.001$ \\
\hline \multicolumn{6}{|l|}{ Complications } \\
\hline Pneumonia & 43,978 & 9.8 & 50,237 & 17.8 & $<0.001$ \\
\hline Empyema & 92 & 0.02 & 284 & 0.10 & $<0.001$ \\
\hline ARDS, acute respiratory failure & 72 & 0.02 & 131 & 0.05 & $<0.001$ \\
\hline Pneumothorax & 175 & 0.04 & 541 & 0.19 & $<0.001$ \\
\hline Pneumomediastinum & 24 & 0.01 & 48 & 0.02 & $<0.001$ \\
\hline
\end{tabular}

ICS, inhaled corticosteroids; ER, emergency room; ICU, intensive care unit; ARDS, acute respiratory distress syndrome.

utilization of secondary and tertiary hospitals, Charlson comorbidity index, hospitalization due to asthma in the previous year, and ICS prescription were associated with an increased OR for pneumonia occurrence. Multiple logistic regression analysis showed that ICS prescription was associated with pneumonia (OR, 1.38; 95\% CI, 1.36-1.41). In addition to ICS prescription, age, sex (female), medical care, use of secondary and tertiary hospitals, and hospitalization due to asthma in the previous year were all associated with pneumonia (Table 4). 
Table 3. Prescribed respiratory medications according to inhaled corticosteroid use

\begin{tabular}{|c|c|c|c|c|c|}
\hline \multirow[t]{2}{*}{ Characteristics } & \multicolumn{2}{|c|}{$\operatorname{ICS}(-)$} & \multicolumn{2}{|c|}{$\operatorname{ICS}(+)$} & \multirow[t]{2}{*}{$P$ value } \\
\hline & No. & $\%$ & No. & $\%$ & \\
\hline Total & 447,855 & 100.0 & 281,488 & 100.0 & \\
\hline ICS & - & 0.0 & 110,542 & 39.3 & $<0.001$ \\
\hline$I C S+L A B A$ & - & 0.0 & 208,475 & 74.1 & $<0.001$ \\
\hline LABA & 2,206 & 0.5 & 2,764 & 1.0 & $<0.001$ \\
\hline LAMA & 5,935 & 1.3 & 27,070 & 9.6 & $<0.001$ \\
\hline LABA + LAMA & 146 & 0.0 & 343 & 0.1 & $<0.001$ \\
\hline SAMA & 7,729 & 1.7 & 29,752 & 10.6 & $<0.001$ \\
\hline SABA & 67,028 & 15.0 & 130,137 & 46.2 & $<0.001$ \\
\hline SABA + SAMA & 2 & 0.0 & 6 & 0.0 & 0.034 \\
\hline LTRA & 286,475 & 64.0 & 180,790 & 64.2 & 0.024 \\
\hline Theophylline & 249,135 & 55.6 & 143,355 & 50.9 & $<0.001$ \\
\hline
\end{tabular}

ICS, inhaled corticosteroids; LABA, long-acting $\beta$-agonists; LAMA, long-acting muscarinic antagonists; SAMA, short-acting muscarinic antagonists; SABA, short-acting $\beta$-agonists; LTRA, leukotriene receptor antagonist.

Table 4. Risk factors for pneumonia in asthmatic patients

\begin{tabular}{|c|c|c|c|c|c|c|c|c|c|c|c|}
\hline \multirow[t]{2}{*}{ Factors } & \multicolumn{2}{|c|}{ Pneumonia (-) } & \multicolumn{2}{|c|}{ Pneumonia (+) } & \multirow[t]{2}{*}{$P$ value } & \multicolumn{2}{|c|}{ Unadjusted } & \multirow[t]{2}{*}{$P$ value } & \multicolumn{2}{|c|}{ Adjusted* $^{*}$} & \multirow[t]{2}{*}{$P$ value } \\
\hline & No. & $\%$ & No. & $\%$ & & OR & $95 \% \mathrm{Cl}$ & & OR & $95 \% \mathrm{Cl}$ & \\
\hline Total & 635,128 & 100.0 & 94,215 & 100.0 & & & & & & & \\
\hline Age (yr) & \multicolumn{2}{|c|}{$56.5 \pm 18.08$} & \multicolumn{2}{|c|}{$61.5 \pm 17.51$} & $<0.001$ & 1.02 & $(1.02-1.02)$ & $<0.001$ & 1.01 & (1.01-1.01) & $<0.001$ \\
\hline \multicolumn{12}{|l|}{ Sex } \\
\hline Male & 255,608 & 40.2 & 38,154 & 40.5 & 0.142 & 1.01 & $(1.00-1.03)$ & 0.141 & 0.92 & $(0.91-0.94)$ & $<0.001$ \\
\hline \multicolumn{12}{|l|}{ Insurance type } \\
\hline Medical insurance & 590,444 & 93.0 & 85,035 & 90.3 & $<0.001$ & 0.70 & $(0.68-0.72)$ & $<0.001$ & 0.95 & $(0.93-0.97)$ & $<0.001$ \\
\hline Medical aid & 44,684 & 7.0 & 9,180 & 9.7 & & 1 (ref) & & & & & \\
\hline \multicolumn{12}{|l|}{ Hospital type } \\
\hline Primary & 529,500 & 83.4 & 69,960 & 74.3 & $<0.001$ & 0.58 & $(0.57-0.59)$ & $<0.001$ & 1.48 & $(1.45-1.51)$ & $<0.001$ \\
\hline Secondary & 43,254 & 6.8 & 13,230 & 14.0 & $<0.001$ & 2.24 & $(2.19-2.28)$ & $<0.001$ & 2.30 & $(2.24-2.35)$ & $<0.001$ \\
\hline Tertiary & 122,630 & 19.3 & 35,413 & 37.6 & $<0.001$ & 2.52 & $(2.48-2.55)$ & $<0.001$ & 2.35 & $(2.30-2.40)$ & $<0.001$ \\
\hline $\begin{array}{l}\text { Charlson comorbidity } \\
\text { index }\end{array}$ & $1.3 \pm 0.70$ & & $1.6 \pm 1.00$ & & $<0.001$ & 1.48 & $(1.47-1.49)$ & $<0.001$ & 1.25 & $(1.24-1.26)$ & $<0.001$ \\
\hline \multicolumn{12}{|l|}{ Hospitalization } \\
\hline$(+)$ & 12,286 & 1.9 & 6,613 & 7.0 & $<0.001$ & 3.83 & $(3.71-3.95)$ & $<0.001$ & 1.89 & $(1.83-1.96)$ & $<0.001$ \\
\hline \multicolumn{12}{|l|}{ ICS use } \\
\hline$(+)$ & 231,251 & 36.4 & 50,237 & 53.3 & $<0.001$ & 2.00 & $(1.97-2.02)$ & $<0.001$ & 1.38 & $(1.36-1.41)$ & $<0.001$ \\
\hline
\end{tabular}

OR, odds ratio; $\mathrm{Cl}$, confidence interval; ICS, inhaled corticosteroids.

*Adjusted factors: age, sex, insurance type, hospital type, Charlson comorbidity index, hospitalization, and ICS use.

\section{DISCUSSION}

We found that ICS use was associated with pneumonia in our asthmatic patients even after adjusting for age, hospital type, comorbidity index, and medical use. ICS users were older, had more comorbidities, and had more medical use and respiratory medicine prescriptions than non-ICS users. They were more likely to be on medical aid and use secondary and tertiary hospitals. Pneumonia and other pulmonary complications were more common among ICS users. However, the high incidence of pneumonia in ICS users might be due to old age and severe disease status.

A previous study showed that chronic bronchitis, asthma, smoking, and ICS are all risk factors for community-acquired pneumonia (CAP) in the general population. ${ }^{21}$ Additional studies revealed that the use of ICS in asthmatic patients increased the risk of pneumonia and that the risk increased as the ICS dose increased; this association was most pronounced in patients receiving fluticasone propionate. ${ }^{22}$ In a Korean study, ICS use increased the risk 
of hospitalization or ED visits due to pneumonia. Conversely, the use of ICS + LABA reduced this risk, suggesting a protective effect against pneumonia. ${ }^{16}$

Many studies have shown that risk factors for pneumonia include age and chronic lung diseases such as COPD or asthma. ${ }^{21,23-27}$ In a meta-analysis of patients with COPD, the risk factors for pneumonia were old age and low FEV1 $(\%) .{ }^{13}$ This suggests that increased pneumonia risk in patients with chronic lung diseases may be due to factors other than ICS, such as age and baseline lung function.

Several recent studies have suggested that ICS use may increase pneumonia risk in COPD patients. ${ }^{912,28}$ However, studies exploring the association of ICS with pneumonia in asthmatic patients are scarce. In one study, smoking and ICS use were risk factors for pneumonia in patients with COPD, but ICS was not associated with pneumonia in asthmatic patients. Use of inhaled anticholinergics is a risk factor for pneumonia in asthmatics ${ }^{18}$; however, in this study, anticholinergics referred only to ipratropium and may not be applicable to LAMA. In our study, the frequency of LAMA, LABA, and LTRA prescription was also significantly higher in ICS users than non-ICS users. Effects of LAMA, LABA, and LTRA on pneumonia risk cannot be ruled out and could confound an assertion of increased pneumonia risk solely associated with ICS. Nonetheless, another study, in COPD patients, showed that the risk of pneumonia in the LAMA use group was lower than in the ICS group and the LABA combined group,${ }^{17}$ and that while the use of ICS without LABA increased the risk of pneumonia, patients using ICS with LABA had a lower risk of pneumonia among patients using ICS. ${ }^{16} \mathrm{As}$ a result, although it is difficult to completely rule out the effects of LAMA, LABA, and LTRA, it is reasonable to assume that the increased risk of pneumonia in the ICS group is likely to be more strongly influenced by ICS than by other medications.

Two other studies have also shown that the use of ICS in asthmatic patients has no effect on CAP, ${ }^{15,19}$ and a third reported that ICS use reduced pneumonia in children with asthma. ${ }^{29}$ Other studies also demonstrate contradictory results from ours. In a retrospective study of pooled randomized trials focusing on budesonide use, inhaled budesonide did not increase pneumonia risk compared to non-ICS treatment and, conversely, it seemed to protect against pneumonia. Further, no difference in pneumonia incidence between the budesonide low-dose and high-dose treatment groups or between the budesonide and fluticasone ICS treatment groups was observed. ${ }^{15}$ Of note, however, this study only examined data from trials sponsored by the pharmaceutical company AstraZeneca, so bias with regard to budesonide cannot be ruled out.

ICS may mitigate risk factors for pneumonia by reducing airway inflammation, improving asthma control, and reducing atelectasis due to mucus impaction, which can be misdiagnosed as pneumonia. Low FEV1 is also a risk factor for pneumonia in and of itself. One report suggested that pneumonia incidence is lower in asthmatic patients than in COPD patients because FEV1 values were higher in the asthmatic patients enrolled in that study than in the COPD patient populations enrolled in conventional studies. ${ }^{15}$ These findings are similar to those of a meta-analysis showing that the use of inhaled budesonide in COPD patients did not increase the risk of pneumonia. ${ }^{13}$ In most studies reporting an increased pneumonia risk with ICS use, the ICS was fluticasone. ${ }^{30}$ An indirect and comparative meta-analysis showed that budesonide/formoterol users had a lower pneumonia risk than fluticasone/salmeterol users, and indicated that difference in ICS type might contribute to differences in pneumonia risk. ${ }^{31}$ 
ICS-mediated pneumonia in COPD patients is thought to stem from ICS-related damage to the host mucosal defense system, as bacteria have been found colonizing the lower respiratory tract in $25 \%$ of COPD patients, ${ }^{32}$ suggesting that bacterial pneumonia may coincide somewhat with ICS use. ${ }^{15}$ In the case of asthma, opposing results have been observed; reportedly, the use of ICS reduced bacterial load and invasion, ${ }^{33-36}$ and was not shown to increase bacterial infection..$^{37}$ In contrast, other studies have reported that ICS use reactivates chronic bacterial infection and induces bacterial colonization. ${ }^{38-40}$ As such, the mechanistic relationship between ICS and pneumonia remains unclear. However, the risk of nontuberculous mycobacterial infection does increase when patients with chronic respiratory diseases use ICS, ${ }^{41,42}$ and the airway microbiota is altered in ICS users compared to normal controls, ${ }^{43}$ offering the possibility that ICS could affect airway microbiota and thereby encourage the development of pneumonia. Although several studies have shown that the use of ICS in COPD patients increases pneumonia risk, it does not increase mortality or protect from death. ${ }^{9,11,12,44,45}$ ICS has even been reported to reduce the severity of pneumonia by decreasing airway inflammation, further confounding a definitive conclusion.

It may seem unusual that, in this study, the proportion of asthma patients using ICS was less than $50 \%$. However, other studies have shown the ICS prescription rate for asthma patients to be only $20 \%$ to $30 \%$, and lower still for those treated at primary care institutions, ${ }^{46-49}$ suggesting it is unlikely that the inhaler prescription rate in this study was abnormally low.

There are some limitations to our study that must be acknowledged. The cross-sectional study design made it difficult to support a causal relationship empirically. Because Asthma Management Adequacy Assessment data by the HIRA are limited to 1 year, it cannot be known how long the patients had been using ICS, nor was there information about whether ICS were started before or after pneumonia development. A prospectively designed study is warranted to evaluate the causal relationship between ICS and pneumonia in more depth. The definitions of asthma and pneumonia used in this study may not represent actual diagnosis, because pulmonary or imaging tests were not directly confirmed, and it is thereby possible that the control group included those with mild illnesses other than asthma, such as allergic rhinitis or chronic cough. These factors may have influenced the results by further reducing the risk of pneumonia in the control group, and these limitations also apply to the drug data. Also, there might be a discrepancy between drug prescription and actual drug use or compliance with the prescription. We could only identify the type of drug, but not the dose or generic prescription name, so assessments of the dose-response relationship between ICS use and pneumonia or differences in pneumonia risk according to specific ICS in use (fluticasone, budesonide, or beclomethasone) were precluded. Although statistically adjusted for other factors, the study results may have been confounded by disease severity. As asthma severity itself has been demonstrated as a risk factor for pneumonia in previous studies, ${ }^{25,50}$ bias could be decreased in future studies by calibrating or measuring severity-related markers. Most importantly, the lack of information on patient smoking history and pulmonary function and the fact that the COPD disease code was not excluded from this study limit the appreciation of an asthma-COPD overlap, wherein COPD cannot be completely distinguished from asthma. In addition, it is possible that ICS/LABA might be prescribed without a pulmonary function test to confirm the diagnosis of asthma in the Korean National Health Insurance system. Specifically, it is possible that a claim for asthma was entered for the ICS prescription even if the patient was suspected of having COPD. Balancing these limitations, there was little possibility of selection bias because our study utilized a nationwide insurance assessment 
database. We also had the advantage of knowing that the asthma-related indicators in one country at a time.

Despite continued controversy regarding ICS use and pneumonia incidence, we found evidence to support the idea that ICS use might be associated with increased pneumonia in asthmatic patients in Korea. Therefore, it is important to acknowledge that ICS use in asthmatic patients may increase the risk of pneumonia and should be followed up for preventative purposes.

\section{ACKNOWLEDGEMENTS}

This study was supported by HIRA (Join Project on Quality Assessment Research), a grant of the Ewha Womans University Research Fund, and the National Research Foundation of Korea (NRF) grant funded by the Korea government (MSIT) (2010-0027945).

\section{REFERENCES}

1. Park HJ, Kim EJ, Yoon D, Lee JK, Chang WS, Lim YM, et al. Prevalence of self-reported allergic diseases and IgE levels: a 2010 KNHANES analysis. Allergy Asthma Immunol Res 2017;9:329-39. PUBMED | CROSSREF

2. Yoo KH, Ahn HR, Park JK, Kim JW, Nam GH, Hong SK, et al. Burden of respiratory disease in Korea: an observational study on allergic rhinitis, asthma, COPD, and rhinosinusitis. Allergy Asthma Immunol Res 2016;8:527-34. PUBMED | CROSSREF

3. Lee YJ, Kwon SH, Hong SH, Nam JH, Song HJ, Lee JS, et al. Health Care utilization and direct costs in mild, moderate, and severe adult asthma: a descriptive study using the 2014 South Korean health insurance database. Clin Ther 2017;39:527-36. PUBMED | CROSSREF

4. Kim MH, Kim SH, Park SY, Ban GY, Kim JH, Jung JW, et al. Characteristics of adult severe refractory asthma in Korea analyzed from the severe asthma registry. Allergy Asthma Immunol Res 2019;11:43-54. PUBMED | CROSSREF

5. Global Initiative for Asthma. Global strategy for asthma management and prevention. Fontana, WI: Global Initiative for Asthma; 2017.

6. Juniper EF, Kline PA, Vanzieleghem MA, Ramsdale EH, O'Byrne PM, Hargreave FE. Effect of long-term treatment with an inhaled corticosteroid (budesonide) on airway hyperresponsiveness and clinical asthma in nonsteroid-dependent asthmatics. Am Rev Respir Dis 1990;142:832-6. PUBMED | CROSSREF

7. Pauwels RA, Löfdahl CG, Postma DS, Tattersfield AE, O'Byrne P, Barnes PJ, et al. Effect of inhaled formoterol and budesonide on exacerbations of asthma. N Engl J Med 1997;337:1405-11. PUBMED | CROSSREF

8. Suissa S, Ernst P, Benayoun S, Baltzan M, Cai B. Low-dose inhaled corticosteroids and the prevention of death from asthma. N Engl J Med 2000;343:332-6. PUBMED | CROSSREF

9. Calverley PM, Anderson JA, Celli B, Ferguson GT, Jenkins C, Jones PW, et al. Salmeterol and fluticasone propionate and survival in chronic obstructive pulmonary disease. N Engl J Med 2007;356:775-89. PUBMED | CROSSREF

10. Ernst P, Gonzalez AV, Brassard P, Suissa S. Inhaled corticosteroid use in chronic obstructive pulmonary disease and the risk of hospitalization for pneumonia. Am J Respir Crit Care Med 2007;176:162-6. PUBMED | CROSSREF

11. Drummond MB, Dasenbrook EC, Pitz MW, Murphy DJ, Fan E. Inhaled corticosteroids in patients with stable chronic obstructive pulmonary disease: a systematic review and meta-analysis. JAMA 2008;300:2407-16.

PUBMED | CROSSREF 
12. Singh S, Amin AV, Loke YK. Long-term use of inhaled corticosteroids and the risk of pneumonia in chronic obstructive pulmonary disease: a meta-analysis. Arch Intern Med 2009;169:219-29. PUBMED | CROSSREF

13. Sin DD, Tashkin D, Zhang X, Radner F, Sjöbring U, Thorén A, et al. Budesonide and the risk of pneumonia: a meta-analysis of individual patient data. Lancet 2009;374:712-9. PUBMED | CROSSREF

14. Kew KM, Seniukovich A. Inhaled steroids and risk of pneumonia for chronic obstructive pulmonary disease. Cochrane Database Syst Rev 2014:CD010115. PUBMED

15. O'Byrne PM, Pedersen S, Carlsson LG, Radner F, Thorén A, Peterson S, et al. Risks of pneumonia in patients with asthma taking inhaled corticosteroids. Am J Respir Crit Care Med 2011;183:589-95. PUBMED | CROSSREF

16. Lee CH, Jang EJ, Hyun MK, Lee NR, Kim K, Yim JJ. Risk of hospital admission or emergency room visit for pneumonia in patients using respiratory inhalers: a case-crossover study. Respirology 2013;18:1116-27. PUBMED

17. Suissa S, Dell'Aniello S, Ernst P. Comparative effectiveness of LABA-ICS versus LAMA as initial treatment in COPD targeted by blood eosinophils: a population-based cohort study. Lancet Respir Med 2018;6:855-62. PUBMED | CROSSREF

18. Almirall J, Bolíbar I, Serra-Prat M, Palomera E, Roig J, Hospital I, et al. Inhaled drugs as risk factors for community-acquired pneumonia. Eur Respir J 2010;36:1080-7. PUBMED | CROSSREF

19. To M, To Y, Yamada H, Ogawa C, Otomo M, Suzuki N, et al. Influence of inhaled corticosteroids on community-acquired pneumonia in patients with bronchial asthma. Intern Med 2004;43:674-8. PUBMED | CROSSREF

20. Charlson ME, Pompei P, Ales KL, MacKenzie CR. A new method of classifying prognostic comorbidity in longitudinal studies: development and validation. J Chronic Dis 1987;40:373-83. PUBMED | CROSSREF

21. Almirall J, Bolíbar I, Serra-Prat M, Roig J, Hospital I, Carandell E, et al. New evidence of risk factors for community-acquired pneumonia: a population-based study. Eur Respir J 2008;31:1274-84. PUBMED | CROSSREF

22. McKeever T, Harrison TW, Hubbard R, Shaw D. Inhaled corticosteroids and the risk of pneumonia in people with asthma: a case-control study. Chest 2013;144:1788-94 PUBMED | CROSSREF

23. Farr BM, Woodhead MA, Macfarlane JT, Bartlett CL, McCraken JS, Wadsworth J, et al. Risk factors for community-acquired pneumonia diagnosed by general practitioners in the community. Respir Med 2000;94:422-7. PUBMED | CROSSREF

24. LaCroix AZ, Lipson S, Miles TP, White L. Prospective study of pneumonia hospitalizations and mortality of U.S. older people: the role of chronic conditions, health behaviors, and nutritional status. Public Health Rep 1989;104:350-60. PUBMED

25. Talbot TR, Hartert TV, Mitchel E, Halasa NB, Arbogast PG, Poehling KA, et al. Asthma as a risk factor for invasive pneumococcal disease. N Engl J Med 2005;352:2082-90. PUBMED | CROSSREF

26. Koivula I, Sten M, Mäkelä PH. Risk factors for pneumonia in the elderly. Am J Med 1994;96:313-20. PUBMED | CROSSREF

27. Juhn YJ, Kita H, Yawn BP, Boyce TG, Yoo KH, McGree ME, et al. Increased risk of serious pneumococcal disease in patients with asthma. J Allergy Clin Immunol 2008;122:719-23. PUBMED | CROSSREF

28. Nannini LJ, Cates CJ, Lasserson TJ, Poole P. Combined corticosteroid and long-acting beta-agonist in one inhaler versus long-acting beta-agonists for chronic obstructive pulmonary disease. Cochrane Database Syst Rev 2007:CD006829. PUBMED

29. Cazeiro C, Silva C, Mayer S, Mariany V, Wainwright CE, Zhang L. Inhaled corticosteroids and respiratory infections in children with asthma: a meta-analysis. Pediatrics 2017;139:139. PUBMED | CROSSREF

30. Marzoratti L, Iannella HA, Waterer GW. Inhaled corticosteroids and the increased risk of pneumonia. Ther Adv Respir Dis 2013;7:225-34. PUBMED | CROSSREF 
31. Halpin DM, Gray J, Edwards SJ, Morais J, Singh D. Budesonide/formoterol vs. salmeterol/fluticasone in COPD: a systematic review and adjusted indirect comparison of pneumonia in randomised controlled trials. Int J Clin Pract 2011;65:764-74. PUBMED | CROSSREF

32. Monsó E, Ruiz J, Rosell A, Manterola J, Fiz J, Morera J, et al. Bacterial infection in chronic obstructive pulmonary disease. A study of stable and exacerbated outpatients using the protected specimen brush. Am J Respir Crit Care Med 1995;152:1316-20. PUBMED | CROSSREF

33. Martin RJ, Chu HW, Honour JM, Harbeck RJ. Airway inflammation and bronchial hyperresponsiveness after Mycoplasma pneumoniae infection in a murine model. Am J Respir Cell Mol Biol 2001;24:577-82. PUBMED | CROSSREF

34. Hansbro PM, Beagley KW, Horvat JC, Gibson PG. Role of atypical bacterial infection of the lung in predisposition/protection of asthma. Pharmacol Ther 2004;101:193-210. PUBMED | CROSSREF

35. Barbier M, Agustí A, Albertí S. Fluticasone propionate reduces bacterial airway epithelial invasion. Eur Respir J 2008;32:1283-8. PUBMED | CROSSREF

36. Dowling RB, Johnson M, Cole PJ, Wilson R. Effect of fluticasone propionate and salmeterol on Pseudomonas aeruginosa infection of the respiratory mucosa in vitro. Eur Respir J 1999;14:363-9. PUBMED | CROSSREF

37. Sasaki A, Ouchi K, Makata H, Hashimoto K, Matsubara T, Furukawa S. The effect of inhaled corticosteroids on Chlamydophila pneumoniae and Mycoplasma pneumoniae infection in children with bronchial asthma. J Infect Chemother 2009;15:99-103. PUBMED | CROSSREF

38. Blotta MH, DeKruyff RH, Umetsu DT. Corticosteroids inhibit IL-12 production in human monocytes and enhance their capacity to induce IL-4 synthesis in CD4+ lymphocytes. J Immunol 1997;158:5589-95. PUBMED

39. Laitinen K, Laurila AL, Leinonen M, Saikku P. Reactivation of Chlamydia pneumoniae infection in mice by cortisone treatment. Infect Immun 1996;64:1488-90. PUBMED

40. Zhang L, Prietsch SO, Mendes AP, Von Groll A, Rocha GP, Carrion L, et al. Inhaled corticosteroids increase the risk of oropharyngeal colonization by Streptococcus pneumoniae in children with asthma. Respirology 2013;18:272-7. PUBMED | CROSSREF

41. Hojo M, Iikura M, Hirano S, Sugiyama H, Kobayashi N, Kudo K. Increased risk of nontuberculous mycobacterial infection in asthmatic patients using long-term inhaled corticosteroid therapy. Respirology 2012;17:185-90. PUBMED | CROSSREF

42. Andréjak C, Nielsen R, Thomsen VO, Duhaut P, Sørensen HT, Thomsen RW. Chronic respiratory disease, inhaled corticosteroids and risk of non-tuberculous mycobacteriosis. Thorax 2013;68:256-62. PUBMED | CROSSREF

43. Hilty M, Burke C, Pedro H, Cardenas P, Bush A, Bossley C, et al. Disordered microbial communities in asthmatic airways. PLoS One 2010;5:e8578. PUBMED | CROSSREF

44. Wedzicha JA, Calverley PM, Seemungal TA, Hagan G, Ansari Z, Stockley RA, et al. The prevention of chronic obstructive pulmonary disease exacerbations by salmeterol/fluticasone propionate or tiotropium bromide. Am J Respir Crit Care Med 2008;177:19-26. PUBMED | CROSSREF

45. Malo de Molina R, Mortensen EM, Restrepo MI, Copeland LA, Pugh MJ, Anzueto A. Inhaled corticosteroid use is associated with lower mortality for subjects with COPD and hospitalised with pneumonia. Eur Respir J 2010;36:751-7. PUBMED | CROSSREF

46. Choi JY, Yoon HK, Lee JH, Yoo KH, Kim BY, Bae HW, et al. Current status of asthma care in South Korea: nationwide the Health Insurance Review and Assessment Service database. J Thorac Dis 2017;9:3208-14. PUBMED | CROSSREF

47. Zeiger RS, Hay JW, Contreras R, Chen W, Quinn VP, Seal B, et al. Asthma costs and utilization in a managed care organization. J Allergy Clin Immunol 2008;121:885-892.e5. PUBMED | CROSSREF

48. Rabe KF, Vermeire PA, Soriano JB, Maier WC. Clinical management of asthma in 1999: the Asthma Insights and Reality in Europe (AIRE) study. Eur Respir J 2000;16:802-7. PUBMED | CROSSREF 
49. Kim CK, Callaway Z, Choi J, Kim HB, Kwon EM, Chang YS, et al. Multicenter adherence study of asthma medication for children in Korea. Allergy Asthma Immunol Res 2019;11:222-30. PUBMED | CROSSREF

50. Klemets P, Lyytikäinen O, Ruutu P, Ollgren J, Kaijalainen T, Leinonen M, et al. Risk of invasive pneumococcal infections among working age adults with asthma. Thorax 2010;65:698-702. PUBMED | CROSSREF 